\title{
Promoting access to dental care in South London: adult patients' perspectives
}

\author{
Sylviana Haji Moris ${ }^{1}$ - Orla Carty ${ }^{2}$ Kristina L. Wanyonyi ${ }^{3,4}$ • Jennifer E. Gallagher ${ }^{3}$ (I)
}

Received: 1 September 2016 / Accepted: 13 July 2017 / Published online: 25 August 2017

(C) The Author(s) 2017. This article is an open access publication

\begin{abstract}
Objective To evaluate patients' views on health service initiatives established to improve uptake of NHS primary dental care amongst adult patients in a socially deprived area, comparing practices with extended and regular contract capacity.

Study design Service evaluation and cross-sectional survey. Method Questionnaire survey of patients attending a random sample of dental practices in three inner-metropolitan boroughs of south London following initiatives to improve access to dental care (across dental practices delivering regular and extended contracts for services) exploring attendance patterns and the influence and awareness of local initiatives to promote access. Results Four hundred fifty adults across 12 dental practices completed questionnaires: $79 \%$ reported attending for routine and $21 \%$ for urgent care. Patients were most aware of banners outside practices, followed by dental advertisements in newspapers. Vouchers for free treatments were considered of the highest possible influence, followed by vouchers for reduced treatment costs and an emergency out-of-hours helpline. Awareness and influence were not aligned, and there was no evidence of difference by practice contract type whilst there were differences by age and type of attendance.
\end{abstract}

Jennifer E. Gallagher

jenny.gallagher@kcl.ac.uk; https://kclpure.kcl.ac.uk/portal/

jenny.gallagher.html

1 Ministry of Health, Brunei Darussalam, Bandar Seri Begawan, Brunei

2 Department of Orthodontics, University of Liverpool, Liverpool, UK

3 King's College London Dental Institute, Division of Patient and Population Health, Denmark Hill Campus, Bessemer Road, London SE5 9RS, UK

4 University of Portsmouth Dental Academy, University of Portsmouth, Portsmouth, UK
Conclusion The findings suggest that financial incentives and emergency services are considered the most influential initiatives for adult patients whose attendance patterns appear to be related to personal circumstances rather than merely being influenced by the provision of information.

Keywords Access $\cdot$ Dentistry $\cdot$ Improving uptake $\cdot$ Barriers to dental care $\cdot$ Dental health $\cdot$ General dental practice

\section{Introduction}

Access to basic health services is a fundamental human right (World Health Organization 2013) and further emphasised as playing a role in addressing global inequalities (Marmot 2008). Access to health care is a complex and multidimensional concept and as a result there are many definitions. Guay (2004) considered access to be a supply and demand issue, encompassing both the availability of dental care as well as the willingness of the patient to seek care. More recently Harris (2013) proposed the construct of dental access as involving the following four concepts: opportunity for access, realised access (utilisation), equity and outcomes. Gulliford and Morgan (2003) describe the factors influencing access as multifaceted and the importance of research on barriers to access. Barriers to dental care have been well researched nationally (Finch et al. 1988; Hill et al. 2013; Kelly et al. 2000) and locally (Borreani et al. 2008, 2010), with Borreani et al. (2008) classifying barriers in older adults as 'active' or 'passive': active barriers include availability, accessibility, cost, fear and features of the dentist, whereas lack of perceived need is a passive barrier. Despite the research into barriers, there is a relative paucity of research on initiatives to improve the uptake of dental care (Gilbert et al. 
2009), and the published literature tends to relate to small local initiatives or policy initiatives (Anderson and Morgan 1992).

In England, the uptake of dental care decreased between 2006 and 2008 following the introduction of a new dental contract in April of 2006. Steele (2009), in a review commissioned by the Secretary of State for Health, reported in 2009 that up to $24 \%$ of the population had difficulty in locating an NHS dentist, and $20 \%$ perceived poor quality of care from NHS dentists. A national 'Dentistry Watch' survey conducted in 2007 on 5212 patients found that $20 \%$ avoided treatment because of cost, while $50 \%$ of all NHS patients found NHS dental charges confusing (Commission for Patient and Public Involvement in Health 2007). It was evident that access to NHS dentistry needed to be improved, and this became a political imperative supported by resources (Department of Health 2009, 2011; Steele 2009). Locally, NHS Primary Care Trusts [PCTs] used the additional resources provided to increase the uptake of NHS dentistry to implement a series of initiatives to address dental uptake in metropolitan inner city area during 2009/10. Individual practices were encouraged to form targets and plans to improve the uptake by dental patients and increase the provision of dental care, which has then been compared with national data. A range of initiatives was funded by local PCTs to improve access including banners, advertisements in local newspapers, advertisements on buses and bus shelters, free toothpaste/brush packs for new patients and cinema advertisements, as listed in Tables 2 and 5. Also some individual practices had further initiatives funded, including free check-up vouchers for new patients and a texting service to remind patients of appointments. Information-based initiatives to improve the uptake of dental care have been evaluated and shown to provide insight into both practitioner and patient perceptions, but with little impact on service uptake (Anderson and Morgan 1992). In a similar way the current study examined the impact of dental access initiatives on patients' awareness and perceived influence in patients in inner city metropolitan areas of London. These boroughs have socially deprived and ethnically diverse populations, with poor dental uptake patterns (Gallagher et al. 2010). At the time, health service data suggested that $56 \%$ of the adults in Lambeth, $51 \%$ in Southwark and 59\% in Lewisham had utilised an NHS dentist in the preceding 24 months based on the local resident population (NHS Digital 2009).

\section{Aim}

To explore the views of adult patients attending primary dental care in inner city practice on initiatives to raise awareness and improve dental access.

\section{Methods}

Dental practices with, and without, extended NHS capacity (referred to as extended and regular practices in this article) were identified and practice principals invited to participate in this research. NHS contracts were across the three boroughs of Lambeth, Southwark and Lewisham in South London. The study was designed to have a power of $80 \%$, at the $5 \%$ significance level, to detect standardised differences of 0.25 and above between extended and regular contracts, for which a total of 256 respondents in each category were required. Therefore, 60 patients were requested per practice to account for a possible $25 \%$ non-response rate.

A questionnaire was developed for adult patients (16 years and over) attending participating dental practices. The selfcompleted questionnaire explored key areas: reasons for dental attendance; awareness of the range of local service initiatives to promote primary dental care during the past year; whether these initiatives were perceived to influence their behaviour to access NHS dental care; barriers to dental care; patient demography. The patient questionnaire was based on previous research: a study on marketing dentistry in Dudley by Anderson and Morgan (1992); the national adult dental health survey questionnaire (Kelly et al. 2000; NHS Digital 2011b); the Commission for Patient and Public Involvement in Health (2007).

The survey instrument consisted of 15 questions in three sections:

\section{Part I: Dental Attendance Pattern}

Part II: Awareness of Initiatives, Influence of Initiatives and Barriers to Care

Part III: Information about the respondent

A five-point Likert scale ranging from 'definitely yes' to 'definitely no' was used as responses to the questions around 'awareness' of initiatives and the reverse of the scale was used on the questions around 'influence' of initiatives.

The patient questionnaire was tested through face-to-face piloting in two dental practices in Lambeth and Lewisham. The respondents were invited to report whether the questionnaire was understandable, and acceptable, as advocated by Bowling (2002). The questionnaire was found to be generally easy to complete and acceptable by the patients. However, based on patient feedback, it was necessary to reword the question relating to the influence of initiatives as these initiatives came, went and varied across the boroughs. It was clear that patients were interpreting the question on whether these had influenced them to include would have used them. Thus the question was amended to explore whether they had or would have changed their behaviour towards access to NHS dental care. This was undertaken with the view that the findings would inform future initiatives. 
The questionnaire was administered by the practice staff to adult patients attending the participating practice in late spring 2010. There was a sign posted at the entrance and in the waiting area identifying that a survey was taking place. Adult patients were given an information sheet about the evaluation and asked if they would like to participate. Those who accepted were asked to complete the questionnaire survey in the waiting room and place it in a designated, sealed box at the reception for the research team; anonymity was assured. The researcher (SHM) made regular visits throughout the week to the participating dental practices to check the progress of the survey and collected completed questionnaires at the end of the week. Paper and computer records were coded by dental practice. The researcher was blind to the nature of the practice contract and unblinding did not occur until analysis was completed.

Quantitative analysis was undertaken using SPSS v21 following data input onto a computer. Descriptive, univariate and factor analyses were conducted to ascertain the awareness of initiatives and their influences on the patients based on sociodemography. Correlation between awareness and influence was measured using Pearson's correlation coefficient. Significance was taken as $\geq 0.05$.

\section{Results}

\section{Participating practices}

Practices were categorised by type of contract (category A, which had regular contracts, while category B had extended contracts) and borough (Lambeth, Southwark and Lewisham). Random sampling continued in each borough until 12 practices had been identified that were willing to participate. Twenty-five out of 37 dental practices invited refused to participate giving the following reasons: the principal dentist not available to speak or always in attendance, too busy, lack of interest and already participating in another study. Of the practices willing to participate in the research, seven had extended and five regular contracts.

\section{Patient respondents}

The target size for the patient questionnaire was 512. As displayed in Table 1, a response of $88 \%(n=450)$ was achieved. The majority had attended for a routine check-up $(79 \% ; n=352)$, were female $(61 \%, n=253$, white $(63 \%$, $n=282)$, from the regular contract practices $(63 \%, n=283)$ and fee paying $(62 \% ; 229)$. The largest age group was in the $35-44$ year age band $(21 \%, n=89)$, with those aged over 75 years the smallest $(2.4 \% n=10)$.

Only 7\% $(n=29)$ of respondents reported being new patients to the dental practices. In contrast, almost two thirds
$(64 \%, n=284)$ indicated that they had been with their dental practice for more than 2 years. Almost four out of five (79\%; $n=352$ ) adults reported attending a routine or planned appointment, with $21 \%(n=93)$ attending for a dental emergency. Out of the 445 adults who responded to the question exploring the rationale for their choice of practice, location $(45 \%, n=200)$ was reported as the most influential factor, followed by reputation $(28 \%, n=125)$. Twenty-two per cent $(n=98)$ suggested other reasons for their choice of practice, the majority of whom reported that they always used this dental practice; this represented $19 \%$ of all respondents $(n=85)$. Only 5\% $(n=22)$ reported both location and reputation as influential in their decision. In terms of location, being near home was the most common reason reported by $39 \%(n=174)$.

The order in which factors influenced choice of dental practice was similar in both extended and regular contract practices, with a slightly higher proportion of respondents from practices with extended contracts $(46 \%, n=77)$ reporting location as important compared with regular contracts $(44 \%, n=123)$. Reputation was reportedly favoured by $31 \%(n=85)$ of respondents from practices with established contract practices compared with $24 \%(n=40)$ from those with extended contracts. Overall, although amongst both men and women, most people favoured location as a factor influencing the choice of practice significantly $(p=0.01)$; more men $(57 \%, n=92)$ selected location compared with women $(37 \%, n=92)$, whilst reputation was favoured by women $(31 \%, n=78 \mathrm{cf} .25 \% ; n=40)$.

\section{General patient awareness and influence of initiatives}

Factor analysis was carried out to identify the constructs in the questionnaire confirming two factors; first their 'awareness of Initiatives' and second, 'influence by initiatives'. The factor loading for each scale ranged between 0.9 and 0.7 for influence of initiatives and 0.7 and 0.57 suggest a good understanding of the questions by the participants. This is displayed in Table 2.

Additionally, Table 2 highlights that respondents reported the highest awareness of banners outside dental practices followed by dental advertisements in newspapers. The most influential initiative was rated as vouchers for free treatments followed by vouchers for reduced treatment costs and banners outside dental practices, with the least influential being dental posters at bus stops. Awareness and influence were not aligned. For example, although patients were most aware of banners, they were only the 4th most influential out of the 12 initiatives examined. There were, however, differences in the overall awareness and influence of the initiatives between groups as shown in Table 3 (awareness) and Table 4 (influence). 
Table 1 Practice and patient characteristics of respondents, $n=450$

\begin{tabular}{|c|c|c|c|}
\hline & & Number & $\begin{array}{l}\text { Per centage } \\
\%\end{array}$ \\
\hline \multicolumn{4}{|l|}{ Practice characteristics } \\
\hline \multirow[t]{2}{*}{ Type of contract $n=450$} & Regular contract (category A) & 283 & 62.9 \\
\hline & Extended contract (category B) & 167 & 37.1 \\
\hline \multirow[t]{3}{*}{ PCT $n=450$} & Lambeth & 185 & 41.1 \\
\hline & Southwark & 112 & 24.9 \\
\hline & Lewisham & 153 & 34 \\
\hline \multicolumn{4}{|l|}{ Patient characteristics } \\
\hline \multirow[t]{2}{*}{$\operatorname{Sex} n=415$} & Male & 162 & 39 \\
\hline & Female & 253 & 61 \\
\hline \multirow[t]{7}{*}{ Age group $n=415$} & $16-24$ & 48 & 11.6 \\
\hline & $25-34$ & 81 & 19.5 \\
\hline & $35-44$ & 89 & 21.4 \\
\hline & $45-54$ & 81 & 19.5 \\
\hline & $55-64$ & 61 & 14.7 \\
\hline & $65-74$ & 45 & 10.8 \\
\hline & 75 and over & 10 & 2.4 \\
\hline \multirow[t]{6}{*}{ Ethnicity $n=413$} & White & 282 & 63 \\
\hline & Asian & 28 & 6 \\
\hline & Chinese & 5 & 1 \\
\hline & Black & 73 & 16 \\
\hline & Mixed ethnicity & 25 & 6 \\
\hline & Other & 4 & 1 \\
\hline \multirow[t]{3}{*}{ NHS payment status $n=369$} & Yes & 229 & 62.1 \\
\hline & No & 138 & 37.4 \\
\hline & Other & 2 & 0.5 \\
\hline \multirow[t]{4}{*}{ Mobility of residence $n=362$} & More than once & 42 & 11.6 \\
\hline & Once & 76 & 21 \\
\hline & Never & 237 & 65.5 \\
\hline & Other & 7 & 1.9 \\
\hline \multirow[t]{4}{*}{ Period with dental practice $n=447$} & More than 2 years & 284 & 63.5 \\
\hline & 1 to 2 years & 65 & 14.5 \\
\hline & Less than a year & 69 & 15.4 \\
\hline & First visit today & 29 & 6.5 \\
\hline \multirow[t]{2}{*}{ Current dental visit $n=445$} & Routine check-up/planned work/other & 352 & 79.1 \\
\hline & Urgent & 93 & 20.9 \\
\hline \multirow{4}{*}{$\begin{array}{l}\text { Main factor in choice of dentist } \\
n=445\end{array}$} & Location & 200 & 44.9 \\
\hline & Reputation & 125 & 28.1 \\
\hline & Both location and reputation & 22 & 4.9 \\
\hline & Others & 98 & 22 \\
\hline \multirow[t]{3}{*}{ Past dental attendance $n=444$} & $\begin{array}{l}\text { Less often or only when having } \\
\text { trouble }\end{array}$ & 124 & 27.9 \\
\hline & About the same & 203 & 45.7 \\
\hline & More often & 117 & 26.4 \\
\hline
\end{tabular}

The findings presented in Tables 3 and 4 suggest that there were no significant differences in awareness and influences of initiatives between the two contract types. There were, however, significant differences by patient group: respondents attending for routine appointments or having a history of regular attendance reported significantly higher overall awareness of initiatives compared with those attending for emergency care $(p=0.03)$. In relation to the influence of 
Table 2 Awareness and influence of initiatives to improve uptake of dental care

\begin{tabular}{|c|c|c|c|c|c|}
\hline & $\begin{array}{l}\text { Cronbach } \\
\text { alpha }\end{array}$ & $\begin{array}{l}\text { Factor } \\
\text { loading }\end{array}$ & Mean & SD & $\mathrm{N}=(331)$ \\
\hline $\begin{array}{l}\text { Scale 1: awareness of initiatives (are you aware of or } \\
\text { have you seen any of the following initiatives?) }\end{array}$ & 0.879 & & & & \\
\hline Banners outside dental practices (most aware) & & 0.566 & 2.89 & 1.256 & 331 \\
\hline Dental advertisements in newspapers & & 0.697 & 2.2 & 1.127 & 331 \\
\hline Dental article in a magazine & & 0.656 & 2.06 & 1.136 & 331 \\
\hline Dental leaflets/flyers & & 0.705 & 2.03 & 1.081 & 331 \\
\hline Dental advertisements on buses & & 0.624 & 1.92 & 1.064 & 331 \\
\hline Emergency out of hours helpline & & 0.665 & 1.91 & 1.086 & 331 \\
\hline Dental posters at bus stops & & 0.65 & 1.68 & 0.915 & 331 \\
\hline PCT pals & & 0.645 & 1.52 & 0.97 & 331 \\
\hline Free toothpaste packs for new patients initiatives? & & 0.622 & 1.52 & 0.929 & 331 \\
\hline Vouchers for reduced cost of treatment & & 0.696 & 1.36 & 0.832 & 331 \\
\hline Removable helpline card in a magazine & & 0.703 & 1.34 & 0.704 & 331 \\
\hline Vouchers for free treatment (least aware) & & 0.667 & 1.28 & 0.719 & 331 \\
\hline $\begin{array}{l}\text { Scale 2: influence of initiatives (which of the } \\
\text { following initiatives } \\
\text { have or would have changed your behaviour } \\
\text { towards access to NHS dental care?) }\end{array}$ & 0.956 & & & & $N=334$ \\
\hline Vouchers for free treatment (most influential) & & 0.743 & 2.31 & 1.338 & 334 \\
\hline Vouchers for reduced cost of treatment & & 0.75 & 2.42 & 1.326 & 334 \\
\hline Emergency out of hours helpline & & 0.799 & 2.71 & 1.236 & 334 \\
\hline Free toothpaste packs for new patients & & 0.784 & 2.91 & 1.304 & 334 \\
\hline Banners outside dental practices & & 0.761 & 2.95 & 1.239 & 334 \\
\hline Dental leaflets/flyers & & 0.891 & 3.07 & 1.166 & 334 \\
\hline PCT pals & & 0.828 & 3.1 & 1.217 & 334 \\
\hline Dental advertisements in newspapers & & 0.88 & 3.13 & 1.202 & 334 \\
\hline Dental article in a magazine & & 0.876 & 3.13 & 1.201 & 334 \\
\hline Removable helpline card in a magazine & & 0.863 & 3.14 & 1.222 & 334 \\
\hline Dental advertisements on buses & & 0.818 & 3.26 & 1.187 & 334 \\
\hline Dental posters at bus stops (least influential) & & 0.842 & 3.28 & 1.166 & 334 \\
\hline
\end{tabular}

1. Scales are reversed with higher awareness marked by a higher mean score, whilst higher influence marked by a low mean score

2. Extraction method: principal component analysis

3. Rotation method: Oblimin with Kaiser normalisation

4. Reliability test: Cronbach alpha initiatives, females were significantly more influenced than males $(p=0.004)$, Lambeth than the other boroughs $(p=0.03)$ and black and Asian groups than White ethnicities $(p=0.035)$, with a gradient by age $(p=0.005)$.

In relation to differences in the preferences for individual initiatives, Table 5 shows that patients from regular contract practices were significantly more likely to report that they would be influenced by vouchers for free treatment than those in the extended contract sites. In terms of dental attendance type, urgent attendees reported being significantly more influenced by reduced cost of treatment and dental leaflets/flyers. When those who reported paying for NHS services were compared with those who did not, the results suggested that free toothpaste, dental leaflets, an emergency dental helpline and flyers appear to be more likely to influence those who do not pay for NHS charges than those who had to pay. Banners outside practices were perceived as the most important influence on respondents who had moved home once, and dental posters on those who had moved home more than once, compared with those who had moved once only. Those who had moved more than once were also more influenced by free treatment vouchers than those who had never moved. All the above were significant at the 0.05 level. Further analysis shows differences in patient preferences between the two contract types and within patient groups as detailed in Table 5. 
Table 3 Univariate analysis of differences between patient and practice characteristics: awareness, $n=450$

\begin{tabular}{|c|c|c|c|c|c|}
\hline \multicolumn{2}{|l|}{ Awareness scale } & \multirow{2}{*}{$\begin{array}{c}\text { Mean } \\
1.9\end{array}$} & \multirow{2}{*}{$\begin{array}{l}\text { SD } \\
0.7\end{array}$} & \multirow{2}{*}{$\begin{array}{l}\mathrm{F}(\mathrm{df}) \\
2.6(330)\end{array}$} & \multirow{2}{*}{$\begin{array}{l}P \\
\text { value }\end{array}$} \\
\hline $\mathrm{PCT} n=450$ & Lambeth & & & & \\
\hline & Southwark & 1.89 & 0.6 & & \\
\hline & Lewisham & 1.7 & 0.6 & & \\
\hline \multirow[t]{2}{*}{ Contract type $n=450$} & Regular & 1.8 & 0.6 & $2.5(330)$ & 0.116 \\
\hline & Extended (additional capacity) & 1.9 & 0.7 & & \\
\hline \multirow[t]{7}{*}{ Age group $n=415$} & $16-24$ & 1.9 & 0.7 & $0.7(314)$ & 0.621 \\
\hline & $25-34$ & 1.9 & 0.6 & & \\
\hline & $35-44$ & 1.9 & 0.7 & & \\
\hline & $45-54$ & 1.8 & 0.6 & & \\
\hline & $55-64$ & 1.7 & 0.6 & & \\
\hline & $65-74$ & 1.6 & 0.5 & & \\
\hline & 75 and over & 1.6 & 0.5 & & \\
\hline \multirow[t]{6}{*}{ Ethnicity $n=413$} & Asian & 1.7 & 0.6 & $0.9(313)$ & 0.453 \\
\hline & Black & 1.9 & 0.7 & & \\
\hline & White & 1.8 & 0.6 & & \\
\hline & Mixed & 2.1 & 1.2 & & \\
\hline & Chinese & 1.7 & 0.8 & & \\
\hline & Other & 2.1 & 0.5 & & \\
\hline \multirow[t]{2}{*}{$\operatorname{Sex} n=415$} & Male & 1.7 & 0.7 & $2.7(311)$ & 0.133 \\
\hline & Female & 1.8 & 0.6 & & \\
\hline \multirow[t]{2}{*}{ Type of current care $N=445$} & $\begin{array}{l}\text { Routine check-up/planned } \\
\text { work/other }\end{array}$ & 1.8 & 0.7 & & \\
\hline & Urgent & 1.7 & 0.5 & $4.9(326)$ & 0.026 \\
\hline \multirow{2}{*}{$\begin{array}{l}\text { Past dental attendance pattern } \\
\quad n=444\end{array}$} & Urgent & 1.6 & 0.6 & $4.8(128)$ & 0.03 \\
\hline & Regular & 1.8 & 0.7 & & \\
\hline \multirow[t]{2}{*}{ Pay for NHS treatment $N=369$} & Yes & 1.8 & 0.6 & $0.01(275)$ & 0.938 \\
\hline & No & 1.8 & 0.7 & & \\
\hline
\end{tabular}

*Bold $p$ values are statistically significant

The higher the score the more aware the group is of overall initiatives
The analysis of age group versus awareness and influence of initiatives required a post-hoc analysis and suggested that dental advertisements on buses and dental posters at bus stops influenced 35-44 year olds significantly more than 16-24 year olds and those over 75 years. Overall, there was a trend towards younger adults considering that free toothpaste packs, reduced or free cost of treatment and dental leaflets/flyers being considered as significantly more influential $(p=0.05)$. Emergency out-of-hours helplines were considered influential, and equally so across age-groups, and this is important amongst older adults who reported less influence of initiatives on their dental attendance.

\section{Barriers to dental treatment}

Although these adults were attendees, barriers to dental care were explored (Fig. 1). The most common barrier was fear of treatment $(39 \%, n=111)$, followed by cost $(38 \%, 110)$ and fear of cost $(38 \%, n=107)$. Additional barriers involved difficulty in getting time off work (36\%, $n=73)$, getting an appointment (34\%, $n=38)$ and locating an NHS dentist in the past $(7 \%, n=17)$.

\section{Discussion}

This research provides insight into the multiple initiatives to improve access to dental care across three inner city boroughs in London and their influence on patients. Vouchers for free treatment were perceived as the most influential option according to patients attending during this period; this is in line with the suggestions made by Boyce et al. (2008), who suggest financial incentives are the most effective in influencing individual choices and are likely to be most effective when used as one element of a wider programme to promote longterm behaviour change. Our findings suggest that location was reported as the most influential in patient's choice of practice, particularly amongst men; women on the other hand were more likely to attend a practice based on its reputation. 
Table 4 Univariate analysis of initiatives scale by patient and practice characteristics: influence, $n=450$

\begin{tabular}{|c|c|c|c|c|c|}
\hline \multicolumn{2}{|l|}{ Influence scale } & \multirow{2}{*}{$\begin{array}{l}\text { Mean } \\
2.8\end{array}$} & \multirow{2}{*}{$\begin{array}{l}\mathrm{S} \\
\mathrm{D} \\
1.0\end{array}$} & \multirow{2}{*}{$\begin{array}{l}\mathrm{F}(\mathrm{df}) \\
3.5(331)\end{array}$} & \multirow{2}{*}{$\begin{array}{l}P \\
\text { value }\end{array}$} \\
\hline PCT $n=450$ & Lambeth & & & & \\
\hline & Southwark & 3.2 & 1.1 & & \\
\hline & Lewisham & 3.0 & 1.0 & & \\
\hline \multirow[t]{2}{*}{ Contract type $n=450$} & Regular & 2.9 & 1.0 & $0.62(333)$ & 0.409 \\
\hline & Extended & 3.0 & 1.0 & & \\
\hline \multirow[t]{7}{*}{ Age group $n=415$} & $16-24$ & 2.8 & 0.8 & $3.2(6312)$ & 0.005 \\
\hline & $25-34$ & 2.9 & 0.9 & & \\
\hline & $35-44$ & 2.8 & 1.0 & & \\
\hline & $45-54$ & 3.0 & 1.0 & & \\
\hline & $55-64$ & 3.4 & 1.2 & & \\
\hline & $65-74$ & 3.2 & 1.0 & & \\
\hline & 75 and over & 3.8 & 1.0 & & \\
\hline \multirow[t]{6}{*}{ Ethnicity $n=413$} & Asian & 2.7 & 1.1 & $2.4(318)$ & 0.035 \\
\hline & Black & 2.6 & 1.1 & & \\
\hline & White & 3.2 & 1.0 & & \\
\hline & Mixed & 3.1 & 1.0 & & \\
\hline & Chinese & 3.2 & 0.3 & & \\
\hline & Other & 2.6 & 0.7 & & \\
\hline \multirow[t]{2}{*}{$\operatorname{Sex} n=415$} & Male & 3.2 & 1.0 & $2.9(316)$ & 0.004 \\
\hline & Female & 2.8 & 1.0 & & \\
\hline \multirow[t]{2}{*}{ Type of current care $N=445$} & $\begin{array}{l}\text { Routine check-up/planned } \\
\text { work }\end{array}$ & 2.9 & 1.0 & $0.39(331)$ & 0.534 \\
\hline & Urgent & 3.0 & 1.0 & & \\
\hline \multirow{2}{*}{$\begin{array}{l}\text { Past dental attendance pattern } \\
\quad n=444\end{array}$} & Urgent & 2.9 & 1.0 & $0.39(331)$ & 0.144 \\
\hline & Regular & 3.2 & 1.0 & & \\
\hline \multirow[t]{2}{*}{ Pay for NHS treatment $N=369$} & Yes & 3.0 & 1.0 & $1.6(281)$ & 0.206 \\
\hline & No & 2.9 & 1.0 & & \\
\hline
\end{tabular}

*Bold $p$ values are statistically significant

The lower the score the more influenced the group is of overall initiatives
Gender-based differences are increasingly recognised as important considerations in developing and providing health services (Department of Health 2008).

\section{Influence of initiatives}

Overall, some of the initiatives were perceived as much more influential than the others with differences in perception shown by age, sex and attendance behaviour. Vouchers for free treatment were perceived as the most influential with an average score of 3.07 (SD 1.17); however, in relation to awareness they were only ranked the 5th highest out of 12 . Conversely, although individuals appear aware of leaflets, they were not reported to be influential on patients' attendance pattern. It appeared that patients were less aware of initiatives they perceived would influence them to attend dental services. This can be explained by the fact that these initiatives, which addressed cost and urgent care, although provided locally, were not available throughout the access improvement programme. Interestingly, mobile information sources from other areas of London (notably buses with dental advertising), which passed regularly through the borough, as previously reported by Anderson and Morgan (1992), were amongst the lowest perceived influence; thus the investment in such advertising should be avoided in future. It is essential to note that the items individuals reported as influential correspond with addressing reported barriers (Borreani et al. 2008; Heaton et al. 2004; Hill et al. 2013). These commonly reported barriers were also similar to the 2009 London survey (Pau and Gallagher 2009), which found the reasons for not attending the dental practice in the last 12 months were linked to personal circumstances rather than difficulties in obtaining access or a lack of information.

In considering the survey findings, the representativeness of respondents must be considered carefully. The majority of respondents had been attending the practice for over 2 years $(64 \%$, $n=284)$, with only $7 \%(n=29)$ reporting attending for the first time. This is consistent with national findings, whereby $61 \%$ of those attending were established patients for over 5 years and 


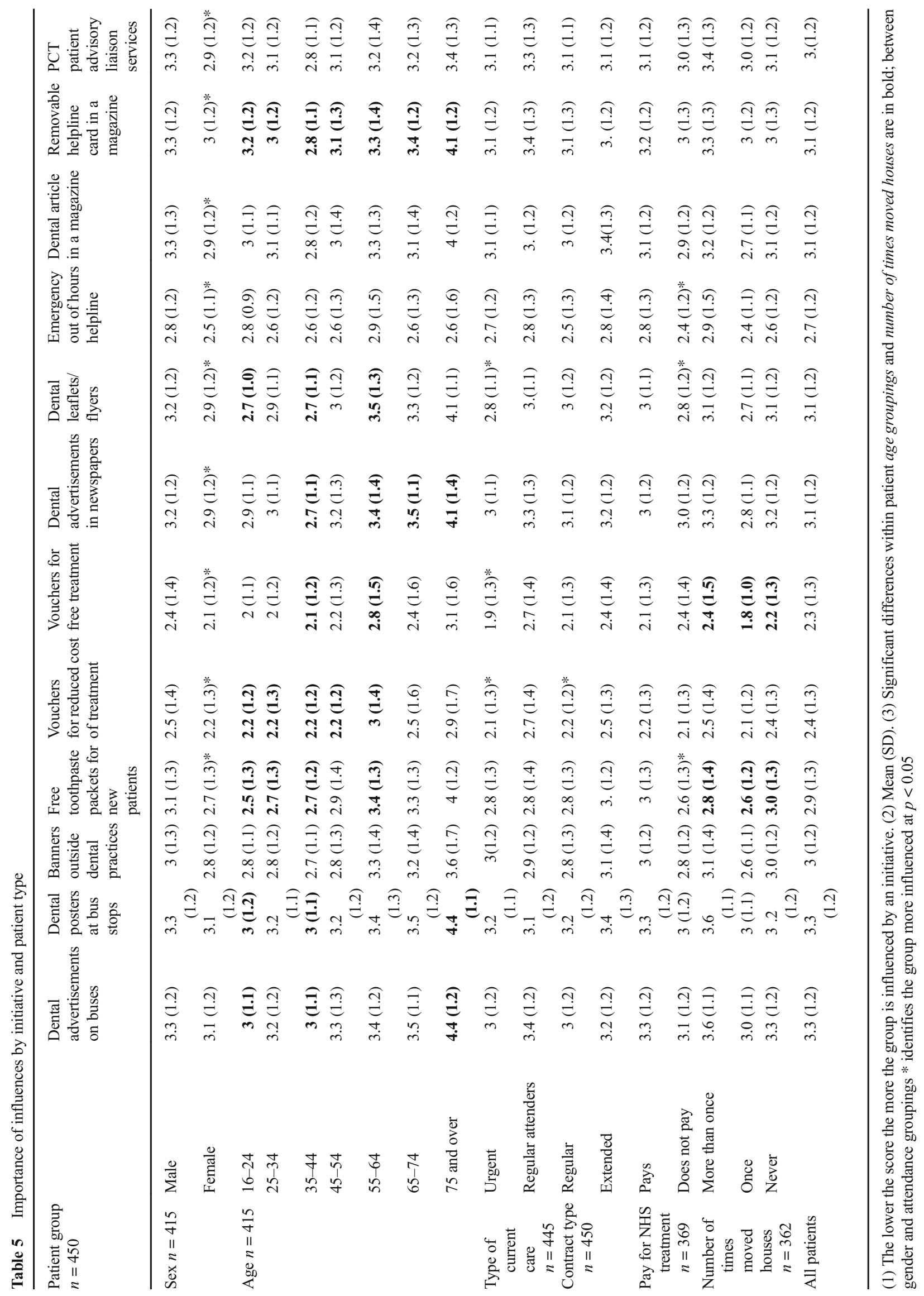


Fig. 1 Reported barriers to dental care for attendees in three inner metropolitan boroughs
In the past did you have a toothache or other dental problem but did NOT see an NHS dentist because of the following

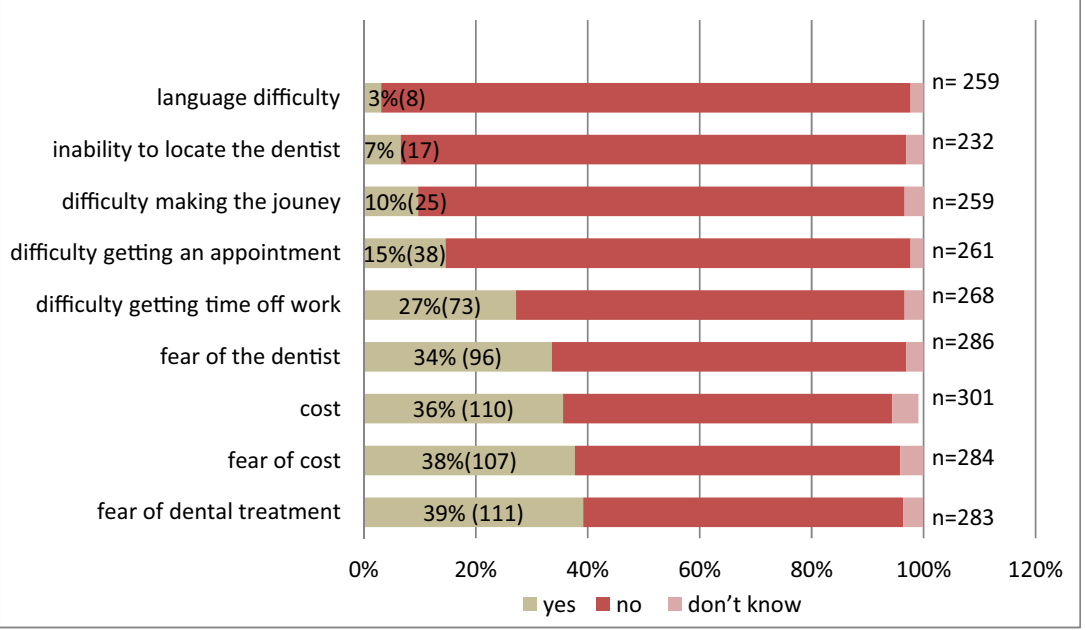

14\% were first time attendees (Hill et al. 2013). However, one in five patients reported attending as a dental emergency, as opposed to routine or planned work. This is higher than the Adult Health Survey 2009 where $64 \%$ reported being regular attenders (Hill et al. 2013), compared with 79\% in this survey, and therefore consistent with being a socially deprived area.

Given local uptake of dental care, which more or less parallels the national level amongst adults, the above arguments seem reasonable. However, given the high levels of population turnover in the boroughs, the long-term relationship of these adults with the practices could be considered high. This suggests that the survey respondents were probably mainly from their regular patient base. Issues with accommodation and affordability of care were reported in this study, in line with the work of Steele (2009), in his independent review of NHS dental services in England and past local surveys (Al-Haboubi et al. 2013); they involved requests for longer opening hours and patient charges to be displayed.

The findings suggest that initiatives to promote dental attendance appealed to patient groups differently; although, given the response rate, differences between the types of practice must be treated with caution. There were, however, significant differences in the awareness of initiatives by different patient groups, with those attending for routine/planned visits being more aware of initiatives and similarly those with a past dental attendance behaviour, which involved regular visits being more aware of initiatives. Furthermore, there were significant differences in relation to the overall influence of initiatives by demography with Asians and Other ethnic groups significantly more influenced by initiatives in general than people of White ethnicity, and females being more influenced than males. The latter is in line with wider evidence, as females have been shown to have better health-seeking behaviour than males in nationwide surveys (NHS Digital 2011a, c), and locally in South East London (Al-Haboubi et al. 2013).

Limitations of the study include the response rate being slightly lower than ideal to compare types of practice and the fact that those who were questioned had already attended the dentist. Nonetheless, it was decided to survey practice attendees in this study as it validated their actual dental attendance. It is important to note that significant resources were poured into this campaign, in terms of both commissioning additional practice capacity and promoting services. Although dental access rates did increase in the area in the period after the initiatives (NHS Digital 2012), this can only be ecologically attributed to the initiatives as other wider societal factors occurring at the time may have played a role and initiatives in other parts of the country as this was a national move to address public concerns and actively promote NHS dentistry.

Emphasis by government on providing information for patients and the public to make choices about their care (Department of Health 2010), is commendable and future initiatives located in inner city areas should ensure that the key barriers are addressed, particularly financial incentives for those who are required to make co-payments (Minister for Health 2016). Initiatives specifically targeted to the relevant populations are likely to be successful in raising dental awareness should they be implemented; however, it may be of value to conduct focussed studies prior to instituting initiatives prior to roll out. By promoting dental attendance, as with this and past initiatives, we may improve awareness and uptake of care for those who might otherwise be 'too busy to attend' or those who perceive themselves to have 'no need', as demonstrated in the West Midlands by Anderson and Morgan (1992), over 2 decades ago. However, we may not affect those who are harder to reach. The findings of this study should prove helpful toplanners and commissioners of dental care on future social marketing strategies. Additionally, the research instrument may be used at varying points in planning, and monitoring initiatives, drawing on the opinions of the general public as well as those who successfully attend for dental care. 


\section{Conclusion}

Adult patients attending primary dental care in three inner-city metropolitan boroughs, during a period when dental care was actively promoted and uptake increased, appear generally to have a long-term relationship with their dental practice. Certain initiatives are perceived to facilitate access more effectively in sub-sections of the populations with financial incentives appearing to have the most attractive influence amongst this socially deprived community, and dental advertisements least. On the other hand, many adult patients certainly appear to be aware of banners located outside dental practices and of dental advertisements in magazines; however, their role in influencing attendance is debatable. Overall it is apparent that dental practices should clearly display their status, charges and emergency helpline numbers for NHS dental care in support of patients.

Acknowledgments The authors wish to acknowledge the patients and staff from dental practices in South East London who contributed to this research.

Authors contributions JG and SHM designed the research, SHM conducted the fieldwork and undertook preliminary analysis of the data. KW undertook secondary data analysis. OC and $\mathrm{KW}$ drafted the paper with JG. All authors contributed to the revising of the paper and approved the final version for publication.

\section{Compliance with ethical standards}

Ethics None required as this was a service evaluation.

Funding This study did not receive direct funding; however, the MSc student was sponsored in her studies by the Government of Brunei Darussalam and the honorary consultant (JEG) was part funded by Lambeth PCT.

Competing interests Prof Gallagher was Dental Public Health Hon Consultant advisor to Lambeth PCT during this project.

Open Access This article is distributed under the terms of the Creative Commons Attribution 4.0 International License (http:// creativecommons.org/licenses/by/4.0/), which permits unrestricted use, distribution, and reproduction in any medium, provided you give appropriate credit to the original author(s) and the source, provide a link to the Creative Commons license, and indicate if changes were made.

\section{References}

Al-Haboubi M, Klass C, Jones K, Bernabé E, Gallagher JE (2013) Inequalities in the use of dental services among adults in inner South East London. Eur J Oral Sci 121:176-181. doi:10.1111/eos.12043

Anderson RJ, Morgan JD (1992) Marketing dentistry: a pilot study in Dudley. Community Dent Health 1:1-220

Borreani E, Wright D, Scambler S, Gallagher JE (2008) Minimising barriers to dental care in older people. BMC Oral Health 8
Borreani E, Jones K, Scambler S, Gallagher JE (2010) Informing the debate on oral healthcare for older people: a qualitative study of older people's views on oral health and oral healthcare. Gerodontology 7:1-8

Bowling A (2002) Research methods in health: investigating health and health services, 2nd edn. Open University Press, Berkshire

Boyce T, Robertson R, Dixon A (2008) Commissioning and behaviour change: kicking bad habits final report. The King's Fund

Commission for Patient and Public Involvement in Health (2007) Dentistry watch: national survey of the NHS dentistry system with views from both patients and dentists. Patient and Public Involvement (PPI) Forums, London

Department of Health (2008) The gender and access to health services study. Department of Health, London

Department of Health (2009) Dental access programme. NHSBSA dental services risk monitoring user group, London

Department of Health (2010) Equity and excellence: liberating the NHS. Department of Health, London

Department of Health (2011) National dental access programme January 2009-March 2011: summary. NHS London, London

Finch H, Keegan J, Ward K (1988) Barriers to the receipt of dental care. Social and community planning research, London

Gallagher JE, Cooper DJ, Wright D (2010) Deprivation and access to dental care, 2005. Community Dent Health 26:92-98

Gilbert D, Scambler S, Pau A, Gallagher JE (2009) Bridging the gap: the role of information in improving dental access. King's College London, London

Guay AH (2004) Access to dental care: solving the problem for underserved populations. J Am Dent Assoc 135:1599-1606

Gulliford M, Morgan M (2003) Access to health care. Routledge, London

Harris RV (2013) Operationalisation of the construct of access to dental care: a position paper and proposed conceptual definitions. Community Dent Health 30:94-101

Heaton LJ, Smith TA, Raybould TP (2004) Factors influencing use of dental services in rural and urban communities: considerations for practitioners in underserved areas. J Dent Educ 68:1081-1089

Hill KB, Chadwick B, Freeman R, O'Sullivan I, Murray JJ (2013) Adult dental health survey 2009: relationships between dental attendance patterns, oral health behaviour and the current barriers to dental care. Br Dent J 214:25-32. doi:10.1038/sj.bdj.2012.1176

Kelly M, Steele J, Nuttall N, et al. (2000) Adult dental health survey, oral health in the United Kingdom, 1998. The Stationary Office, London

Marmot M (2008) Closing the gap in a generation: health equity through action on the social determinants of health. World Health Organization, Geneva

Minister for Health (2016) NHS dental charges from April 2016. UK Government, London

NHS Digital (2009) NHS dental statistics for England, 2008/09. NHS digital, London

NHS Digital (2011a) Executive summary: adult dental health survey, 2009. The Health and Social Care Information Centre. http://content.digital. nhs.uk/pubs/dentalsurveyfullreport09. Accessed 20 Feb 2017

NHS Digital (2011b) Technical report: adult dental health survey, 2009. The Health and Social Care Information Centre, London

NHS Digital (2011c) Theme 8. Access and barriers to care - a report form the Adult Dental Health Survey, 2009. The Health and Social Care Information Centre, London

NHS Digital (2012) NHS dental statistics for England, 2011/12. NHS Digital, London

Pau A, Gallagher JE (2009) Oral health needs assessment and strategy for NHS lambeth. Kings' College London Dental Institute \& NHS Lambeth, London

Steele J (2009) Review of NHS dental services in England: an independent review. Department of Health, London

World Health Organization (2013) World health report 2013: research for universal health coverage WHO, Geneva 